\title{
Iodine 131 treatment for differentiated thyroid carcinoma in patients with end stage renal failure: Dosimetric, radiation safety, and practical considerations
}

\author{
Caliope Alevizaki, ${ }^{1}$ Michael Molfetas, ${ }^{1}$ Alexandros Samartzis, ${ }^{1}$ Barbara Vlassopoulou, ${ }^{2}$ \\ Charalambos Vassilopoulos, ${ }^{2}$ Phoedi Rondogianni, ${ }^{3}$ Sofia Kottou, ${ }^{4}$ \\ Valsamis Hadjiconstantinou, ${ }^{5}$ Maria Alevizaki ${ }^{6}$
}

${ }^{1}$ Medical Physics Laboratory, ${ }^{2}$ Endocrinology Department, ${ }^{3}$ Nuclear Medicine Department and ${ }^{5}$ Nephrology Department, Evangelismos Hospital Athens, ${ }^{4}$ Department of Medical Physics, Athens University School of Medicine and ${ }^{6}$ Endocrine Unit, Evgenideion Hospital, Athens University School of Medicine

\begin{abstract}
BACKGROUND: Iodine 131 ablation following total thyroidectomy is considered an indispensable element of successful treatment of differentiated thyroid carcinoma (DTC). Because of the essential role of the kidneys in iodine clearance, ${ }^{131}$ I therapy of DTC in patients with end stage renal disease, particularly those maintained on haemodialysis, present a number of special features: the ${ }^{131}$ I activity needs to be modified, the haemodialysis sessions need to be adjusted at the time of ${ }^{131}$ I therapy, and there are radiation safety considerations during dialysis. There is considerable controversy over these crucial questions in the reports published so far in the literature, which concern a total of fourteen patients. OBJECTIVE: The aim of our study was to present our experience on ${ }^{131}$ I treatment of 5 DTC patients with end stage renal disease. DESIGN: The data of 5 DTC patients with end stage renal disease, treated with ${ }^{131} I$, were retrospectively analysed; four cases were treated for remnant ablation and one for locoregional progression. In order to allow for prolonged plasma clearance of ${ }^{131} \mathrm{I}$, we used a lower activity of radioiodine, reduced to roughly $40-50 \%$ of the empirically calculated activity used for normal individuals; dialysis sessions were performed immediately before and at 48 hours after ${ }^{131}$ I administration. All patients had ${ }^{131}$ I retention measurements performed post dialysis; in two of them some additional measurements such as iodine clearances were also performed. RESULTS: None of the patients experienced any short-term side effects, while they all had undetectable thyroglobulin levels on the first post therapy evaluation off thyroxine. ${ }^{131} I$ elimination in the first haemodialysis was about $60 \%$. Staff incidental exposure and ${ }^{131}$ I contamination were insignificant. CONCLUSIONS: On the basis of our experience, an empiric activity of 40-50\% of that used for normal individuals appears to be effective as well as safe. These encouraging findings are discussed in relation with other reports in the literature.
\end{abstract}

Key words: Differentiated thyroid carcinoma, End stage renal failure, ${ }^{131}$ I therapy 


\section{INTRODUCTION}

Well differentiated thyroid carcinoma (DTC) is curable in most cases if diagnosed early and treated promptly. Although there is still some controversy in theory as to the necessity for radioiodine use in cases of small encapsulated tumours, Iodine $131\left({ }^{131} \mathrm{I}\right)$ radio-ablation of thyroid remnants is recommended in most cases of DTC following total thyroidectomy. ${ }^{1}$ This treatment is essential for the follow-up of such patients allowing the reduction of plasma thyroglobulin (Tg) to non-detectable levels. The latter, when performed under TSH stimulation, is the most sensitive marker of disease-free status. Radioiodine treatment is an important contributing factor for preventing recurrences and assuring longer disease free survival; furthermore, it is relatively easy to administer and essentially free of serious side effects. ${ }^{2,3}$

Occasionally, cases of DTC are diagnosed in patients who already have end stage renal failure (ESRF). It is desirable that these patients also have the additional benefit of ${ }^{131} \mathrm{I}$ treatment after total thyroidectomy; furthermore, recurrences or progression of DTC may also occur in patients already treated for such tumours before developing end stage renal disease (ESRD); these will also require ${ }^{131}$ I treatment. ${ }^{4-6}$

Since thyroid cancer is a relatively uncommon tumour and the well differentiated type (which accounts for about $90 \%$ of cases) has a very prolonged course, no prospective randomized trials have ever been possible for optimizing activities and procedures. Most practitioners, relying on the results of cohort studies and their own experience, have developed suitable protocols for treatment of their patients. ${ }^{2}$ However, while treatment with ${ }^{131} \mathrm{I}$ is fairly straightforward in the otherwise healthy patient, the administration of ${ }^{131} \mathrm{I}$ to patients with ESRD presents a number of practical and theoretical problems, which are reflected in the cases that have been published so far in the literature. ${ }^{6}$

In the normal individual the kidneys are the thyroid's main competitor for clearing iodide from the blood stream. In the case of renal failure, the activity of ${ }^{131} \mathrm{I}$ to be administered will need adjustment. Absence of any appreciable kidney clearance would affect (through higher plasma iodide 131 concentrations and prolonged time of elimination) both the radiation dose delivered to the remnants of functioning thyroid tissue (normal and extra-thyroidal) as well as to the whole body, particularly the dose to the bone marrow, a consideration which is of particular importance in patients with seriously compromised health.

The timing of haemodialysis in relation to the time point of administration of the therapeutic dose of ${ }^{131}$ I may also be very important in this respect, as it affects the availability of radioiodine to thyroid cells through alterations affecting both the plasma levels as well as the clearance of ${ }^{131}$ I from the circulation. ${ }^{5,6}$ Furthermore, radiation safety regulations, as well as purely practical problems arising from radiation phobia, may present a further challenge in treating the ESRD patient with ${ }^{131} \mathrm{I}$.

Over the last couple of decades about ten papers have been published reporting results on 14 cases of patients on haemodialysis who received twenty treatments with ${ }^{131} \mathrm{I}^{4-13}$ These have recently been reviewed by Holst et $\mathrm{al}^{6}$ on the occasion of ${ }^{131} \mathrm{I}$ treatment for DTC of one of their patients. A further three cases of ${ }^{131}$ I treatment in patients on continuous peritoneal dialysis (CPD) have been published. ${ }^{14,15}$ It is of interest to note that hardly any two of the papers published so far agree with each other as to the procedure to be followed, the optimal ${ }^{131}$ I activity to be used, and the best haemodialysis schedule for these patients.

For this reason we thought it might be of interest to present our own experience with five patients suffering from ESRD, who were treated with ${ }^{131} \mathrm{I}$ for DTC; the first of these cases was treated approximately 22 years ago and the other four quite recently. In view of the difficulties involved it would be reasonable to expect that only by pooling as much experience as there is available from different centres will it ever be possible to arrive at some useful conclusions concerning ${ }^{131} \mathrm{I}$ treatment of thyroid cancer in end stage renal failure, despite the fact that this will inevitably involve different procedures and variability in patients' characteristics. The most critical question that needs to be answered is what quantity of iodine 131 should be used to effectively treat the tumour without unduly increasing the risk of side-effects. 


\section{PATIENTS AND METHODS}

Since, as mentioned in the introduction, the first of the patients presented in this paper was treated more than 20 years ago, and since none of the patients was attending our thyroid clinic before ${ }^{131} \mathrm{I}$ treatment, there was wide variation in the information which was available for this analysis. Thus, only the quantity of ${ }^{131} \mathrm{I}$ administered, radiation dose to the physician attending the $1^{\text {st }}$ dialysis, and the status at first follow-up was available for the first patient, while more detailed information could be ascertained in some of the other patients.

All five patients had a histological diagnosis of papillary thyroid carcinoma; in four cases the purpose of treatment was thyroid remnant ablation after total thyroidectomy, while one patient (case No. 2) was treated for progression of DTC, which had first been treated more than 20 years earlier and had been considered to be in complete remission for nearly 15 years. All these patients were negative for anti-Tg antibodies.

Details of the 5 patients along with the ${ }^{131}$ I activities administered are summarized in Table 1. Patients No. 1, 2, 4, and 5 were on maintenance haemodialysis treatment; patient No. 3 was on intermittent peritoneal dialysis (IPD) and was included in this analysis because IPD cases are considered very similar to dialysis patients so far as the handling of ${ }^{131} \mathrm{I}$ is concerned. ${ }^{16}$ Case No. 2, who was the only patient in this series treated for DTC progression, was a highly intelligent and motivated woman and willing to co-operate. Thus, in this patient a more detailed investigation of the fate of ${ }^{131} \mathrm{I}$ administered was attempted. Since this case history was known in more details, it is briefly presented separately.

\section{Patient No. 2}

A 48-year old woman had been subjected to total thyroidectomy in 1981 and a multifocal papillary adenocarcinoma was diagnosed; an ablative activity of $1850 \mathrm{MBq}(50 \mathrm{mCi})$ of ${ }^{131} \mathrm{I}$ had subsequently been administered. The absence of functioning thyroid tissue was confirmed by whole body scan and nondetectable thyroglobulin $(\mathrm{Tg})$ levels after thyroxine (T4) withdrawal. She was subsequently placed on T4 suppression treatment. In 1994 she developed renal insufficiency and by the end of 2002 required maintenance haemodialysis. An elevated Tg of 120 $\mathrm{ng} / \mathrm{ml}$ was found at follow-up in 1996. Further imaging and frequent follow-up was recommended; however, she was lost to follow-up for several years until a mass on the left side of the neck was noted. A block dissection was performed, resulting in the diagnosis of metastatic thyroid carcinoma; the patient was subsequently referred for additional adjunctive radioiodine treatment as her $\mathrm{Tg}$ levels were above the institutional cut-off levels and she had measurable uptake in the neck. An activity of about 5550 MBq (150mCi) would ordinarily be administered but because of the renal problem this was adjusted to $2590 \mathrm{MBq}(70 \mathrm{mCi})$, almost half the activity usually prescribed. Her pre-treatment $\mathrm{Tg}$ was $2 \mathrm{ng} / \mathrm{ml}$ and the ${ }^{131}$ I uptake at 48 hours was $1.5 \%$.

\section{Activities of ${ }^{131}$ I administered}

At the time of treatment of our first case the only information available in the literature on ${ }^{131}$ I treatment in ESRD was the case published by Howard et al. ${ }^{4}$ These authors had reduced their standard ${ }^{131} \mathrm{I}$ therapy activity by half and recommended delaying

Table 1. Characteristics and aim of treatment for patients included in the study.

\begin{tabular}{ccccl}
\hline & Patient & & MBq $(\mathbf{m C i}){ }^{\mathbf{1 3 1} \mathbf{I}}$ & \multicolumn{1}{c}{ Aim of treatment } \\
\cline { 1 - 3 } No & Gender & Age (years) & & \\
\hline 1 & M & 52 & $1110(30)$ & Remnant ablation after near total thyroidectomy \\
2 & F & 48 & $2590(70)$ & Treatment of recurrence with locoregional progress* \\
3 & M & 65 & $1480(40)$ & Remnant ablation after total thyroidectomy \\
4 & M & 45 & $1295(35)$ & Remnant ablation after total thyroidectomy \\
5 & F & 38 & $1295(35)$ & Remnant ablation after total thyroidectomy \\
\hline
\end{tabular}

*Total thyroidectomy and $1850 \mathrm{MBq}(50 \mathrm{mCi}){ }^{131} \mathrm{I} 22$ years earlier + L neck block dissection, M: male, F: female 
the $1^{\text {st }}$ post-treatment dialysis for about 48 hours so as to allow time for maximum thyroid uptake of ${ }^{131}$ I. The $50 \%$ reduction was in agreement with our own experience of ${ }^{131} \mathrm{I}$ kinetics: modal thyroid uptake value at $48 \mathrm{hrs}$ for the normal population in Greece at that time was $50 \% ;{ }^{17}$ normal kidney elimination of ${ }^{131} \mathrm{I}$ in our population could be assumed to be roughly $50 \%$, so it was empirically decided to adjust the activity of ${ }^{131}$ I to about 40 to $50 \%$ of that prescribed for patients with normal kidney function. No immediate side-effects of ${ }^{131}$ I were apparent in our patient, who was reported as free of evidence of functioning thyroid tissue at 9 months after treatment. Thus, this policy as to time of dialyses and reduction of the ${ }^{131} \mathrm{I}$ activity to about $50 \%$ was carried on in the subsequent patients with ESRD, particularly since the Iodine 131 activities calculated for our subsequent cases $(35-40 \mathrm{mCi}$ for ablation and $70 \mathrm{mCi}$ for a recurrence) were similar to or lower than those used by other authors in more recent literature. ${ }^{5,7,8,10}$

\section{Procedure of ${ }^{131}$ I treatment}

All patients were treated while hospitalized in the special shielded ${ }^{131}$ I ward of our hospital. The radioiodine was administered in a capsule form by the hospital physicist and the usual safety instructions were given in writing. The patients were also encouraged to drink liquids as much as the attending nephrologist allowed in each case.

\section{Procedure during the 1st post-treatment dialysis session}

The equipment used for dialysis was a Gambro AK95 with polysulfone dialyser. The $1^{\text {st }}$ dialysis session was carried out on the 3rd day, approximately $48 \mathrm{hrs}$ after the administration of radioiodine. The dialysis time was chosen for both medical and nonmedical reasons, i.e. to allow maximum ${ }^{131}$ I uptake and minimize radiation exposure to the nursing and auxiliary staff. In all cases the medical physicist informed the staff of the renal unit about radiation protection issues and gave individual radiation dosimeters to those immediately involved with the patient. The physicist remained in the vicinity of the haemodialysis ward throughout the first post- ${ }^{131} \mathrm{I}$ treatment dialysis session to be available for any possible problems of radiation safety and radioactive contamination. No shielding for radiation was judged necessary and the infection limiting equipment (gloves, etc) was considered adequate protection for radioactive contamination. This was confirmed by monitoring all bedding and dialysis equipment after the patient's removal from the ward.

\section{Staff radiation dosimetry}

Radiation exposure of the staff involved was measured by thermoluminescence dosimetry (TLD) using LiF dosimeters, as described in detail in a previous publication. ${ }^{18}$ This facility was not available at the time of the first patient's treatment; for this reason a film badge dosimeter was used in that particular case.

\section{Patient measurements}

Four of the 5 patients had at least four measurements of ${ }^{131}$ I body retention: one a few minutes after radioiodine ${ }^{131} \mathrm{I}$ administration for reference, one just before and just after each dialysis session, and a final one at the time of discharge from the hospital. In addition to these, patient No. 2 had further daily measurements so that more detailed information about radioiodine kinetics could be obtained in this case. This patient was asked to collect 24-hour urine for the first two post-therapy days, as well as for the 24 hours immediately following her $1^{\text {st }}$ dialysis session. Finally, a plasma sample was obtained concurrently to her pre-dialysis and post-dialysis external measurement, and clearance of ${ }^{131} \mathrm{I}$ by the dialysis machine could thus be calculated. The plasma samples at the corresponding times were also obtained in patient No. 5 .

\section{External measurements}

The required number of external measurements was carried out with a calibrated ionization chamber Inovision $451 \mathrm{P}$ DE SI, with the patient standing at a distance of one meter.

\section{Urine and plasma samples radioactivity measurements}

These were carried out in $1 \mathrm{ml}$ aliquots of plasma or urine with a Packard Cobra well-type automatic gamma spectrometer together with a sample of a standard made up with an exactly known quantity of ${ }^{131}$ I suitably diluted. The volume of urine was also carefully measured and marked in those cases where 
urinary measurements were performed.

\section{Calculations}

All external measurements that were carried out in these patients were expressed in per cent of administered activity by referring them to the first external measurement that each patient had shown a few minutes after they had received their ${ }^{131} \mathrm{I}$ dose.

The body retention of ${ }^{131} \mathrm{I}$ at the end of each dialysis session was similarly calculated from the external measurements performed before and after the relevant session; the quantity of ${ }^{131} \mathrm{I}$ removed by haemodialysis was also calculated.

\section{${ }^{131}$ I clearances}

In the two cases where plasma radioactivity measurements during dialysis were available, the plasma radioiodine clearances were calculated using the classic clearance formula:

$$
\begin{gathered}
\text { Clearance }=\left({ }^{131} \text { I excreted }\right) /\left[\left({ }^{131}\right.\right. \text { I plasma } \\
\text { concentration }) *(\text { dialysis duration })]
\end{gathered}
$$

where the quantity of ${ }^{131} \mathrm{I}$ excreted was calculated from the pre-dialysis and post-dialysis radioactivity measurements and the ${ }^{131} \mathrm{I}$ plasma concentration in mid-session was calculated from the respective plasma samples, assuming mono-exponential concentration versus time curve. The clearances were then expressed in $\mathrm{ml} / \mathrm{min}$ as calculated from the duration of the dialysis session. In the patient in whom urine collections had been carried out, the same formula was used to calculate the residual iodine renal clearance; only the quantity of ${ }^{131}$ I excreted was the quantity of ${ }^{131} \mathrm{I}$ found in the patient's urine for each 24-hour period.

\section{RESULTS}

\section{${ }^{131}$ I administration}

None of the five patients experienced any particular discomfort during hospitalization for ${ }^{131} \mathrm{I}$ administration and the first four were reported to be free of thyroid remnants at their first post-treatment evaluation: patients 2-5 had undetectable Tg levels (a marker not available at the time of treatment of the 1 st patient) and are reported as free of recurrence 3 years later, with the exception of the fifth patient whose treatment was too recent for further valid follow-up information. All the patients had their first treatment by dialysis approximately $48 \mathrm{hrs}$ after the radioiodine treatment. The dialysis equipment and each patient's bedding were checked with a survey meter and no appreciable residual Iodine-131 contamination was detected. Since there was small residual non-removable activity of radioiodine in the dialyser in two of the cases, these were taken by the medical physicist and sealed in plastic containers till the radioactivity decayed.

\section{Radiation exposure to the staff of the renal ward}

Table 2 shows the radiation doses that were recorded by the TLD dosimeters carried by the staff of the renal ward and by the nearest patient; these were found in all cases negligible. At the time of treatment of the $1^{\text {st }}$ patient, only film badge dosimetry was available to us, which showed exposure of $<200 \mu \mathrm{Gy}$ i.e. below the method's detection limit.

\section{Dialysis disposal of ${ }^{131} \mathrm{I}$}

Table 3 shows the ${ }^{131}$ I disposal during the $1^{\text {st }}$ dialysis session for the patients in whom this information was available, and the corresponding information for the $2^{\text {nd }}$ dialysis session for patients 2 and 5 who had their 96-hour dialysis session during hospitalization as well. The fraction of ${ }^{131} \mathrm{I}$ removed by dialysis varied from 50 to $65 \%$ for the first session $(85 \%$ for the case on IPD) and the remaining activity was further reduced to 35 and $57 \%$ by the $2^{\text {nd }}$ session (in cases 2 and 5). In the last column of Table 3 the activity burden at discharge from the hospital is shown. This was in all cases well below the limits allowed by radiation safety regulations.

\section{${ }^{131}$ I clearance during hospitalization}

Patient 2 had a more detailed study: residual body activity of ${ }^{131} \mathrm{I}$ was regularly monitored by external $\gamma$-radiation counter during her four-day hospitalization. At the beginning as well as at the end of the first dialysis session, aliquots of plasma were obtained and their ${ }^{131}$ I activity was compared with the results of external measurements. The ratio of the external measurements, i.e. residual activity after $5 \mathrm{hr}$ - dialysis, in $\%$ of the ${ }^{131} \mathrm{I}$ burden at the start of the treatment session, was 0.40 . This was very similar to the ratio of ${ }^{131}$ I concentration in the plasma samples at beginning 
Table 2. Staff radiation dose measurements during haemodialysis ( $\mu \mathrm{Gy})$.

\begin{tabular}{|c|c|c|c|c|c|}
\hline \multirow{2}{*}{$\begin{array}{l}\text { Patients } \\
\text { Number }\end{array}$} & \multicolumn{5}{|c|}{ Radiation dose recorded by TLD dosimeters worn by: } \\
\hline & Physician & Ward sister & Nurse A & Nurse B & Next bed \\
\hline 1 & $<200^{*}$ & & & & \\
\hline 2 & - & 40 & 40 & 10 & $<10$ \\
\hline 3 & - & $<10$ & 10 & & $<10$ \\
\hline 4 & - & & & & \\
\hline 5 & - & & 10 & & \\
\hline
\end{tabular}

*film badge measurement: detection limit of the method

Table 3. ${ }^{131}$ I activity handled by haemodialysis.

\begin{tabular}{|c|c|c|c|c|}
\hline Patients Number & Time (hrs) & $\%$ remaining & $\mathrm{MBq}(\mathrm{mCi})$ removed & Residual MBq (mCi)* \\
\hline \multicolumn{5}{|l|}{2.} \\
\hline $1^{\text {st }}$ haemodialysis & 48 & 40.8 & $988(26.7)$ & $122(3.3)$ \\
\hline $2^{\text {nd }}$ haemodialysis & 96 & 35.1 & $226(6.1)$ & \\
\hline 3. $1^{\text {st }}$ haemodialysis & 48 & 47.1 & $574(15.5)$ & $437(11.8)$ \\
\hline 4. [IPD session] & 48 & {$[14.0]$} & {$[1092][(29.5)]$} & $152(4.1)$ \\
\hline \multicolumn{5}{|l|}{5.} \\
\hline $1^{\text {st }}$ Haemodialysis & 48 & 50.0 & $544(14.7)$ & \\
\hline $2^{\text {nd }}$ Haemodialysis & 96 & 57.0 & $200(5.4)$ & $192(5.2)$ \\
\hline
\end{tabular}

* at discharge from hospital

and end of this dialysis session, which was found to be 0.378 . Both external radiation and plasma measurements prior to initiation of the first haemodialysis session and immediately after the end gave identical ratios of 0.50 in case No. 5, in which these measurements were available.

Figure 1 shows the elimination of ${ }^{131}$ I activity versus time for patient 2 , as calculated by external measurements of ${ }^{131}$ I body retention. Two lines are shown, one corrected for ${ }^{131}$ I radioactive decay and one based on the actual measurements which indicate the effect of ${ }^{131} \mathrm{I}$ biological elimination and the combined effect of biological and radioisotopic decay (effective half life), respectively. As shown by the graph, the elimination of ${ }^{131} \mathrm{I}$ was much slower during day 1 in comparison to day 2 post-treatment, probably due to redistribution of iodine with increasing time elapsed since the last dialysis session. By averaging ${ }^{131}$ I elimination over the 48 hours, an effective half life equal to 76.7 hours for ${ }^{131} \mathrm{I}$ body retention was calculated corresponding to a biological half life of $127.6 \mathrm{hrs}$,

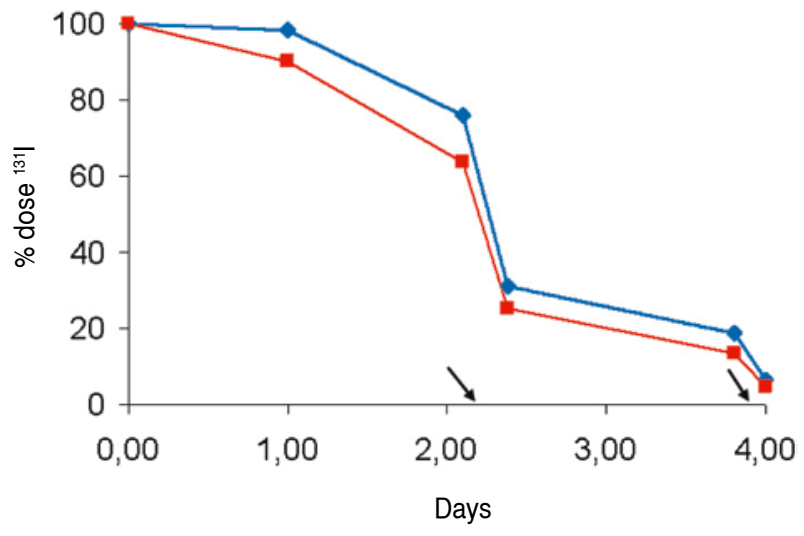

Figure 1. Graph showing ${ }^{131} \mathrm{I}$ body retention versus time in patient No. 2, corrected (blue line) and uncorrected (red line) for radioactive decay, expressed in $\%$ of therapy dose. The arrows indicate haemodialysis sessions.

excluding dialysis. This pattern corresponds to the information given by the 3 consecutive $24 \mathrm{hr}$ urine collections for this patient; as shown in the upper part of Table 4, the percentage of ${ }^{131} \mathrm{I}$ activity found 
Table 4. Urinary and Dialysis Disposal and Clearance of ${ }^{131} \mathrm{I}$ in patients 2 and 5.

\begin{tabular}{|c|c|c|c|}
\hline Patient 2 & & & \\
\hline $\begin{array}{l}\text { Urinary } \\
\text { excretion }\end{array}$ & $\begin{array}{c}\text { volume } \\
(\mathrm{ml})\end{array}$ & $\%$ dose in urine & $\begin{array}{c}{ }^{131} \text { I clearance } \\
(\mathrm{ml} / \mathrm{min})\end{array}$ \\
\hline $1^{\text {st }}$ day (24hr) & 290 & 1.45 & 0.5 \\
\hline $2^{\text {nd }}$ day (48hr) & 780 & 5.49 & 3.1 \\
\hline $3^{\text {rd }}$ day $(72 \mathrm{hr})$ & 270 & 0.7 & 1.7 \\
\hline $\begin{array}{l}\text { Removal } \\
\text { by dialysis }\end{array}$ & & $\begin{array}{c}\% \text { of body } \\
\text { burden }\end{array}$ & $\begin{array}{c}{ }^{131} \text { I clearance } \\
(\mathrm{ml} / \mathrm{min})\end{array}$ \\
\hline At 48 hrs & & 60 & $146(161)^{*}$ \\
\hline At $96 \mathrm{hrs}$ & & 64 & $157(173)^{*}$ \\
\hline
\end{tabular}

\begin{tabular}{lcc}
\hline Patient $\mathbf{5}$ & $\begin{array}{c}\text { \% of body } \\
\text { burden }\end{array}$ & $\begin{array}{c}{ }^{131} \text { I clearance } \\
\text { (ml/min) }\end{array}$ \\
$\begin{array}{l}\text { Removal } \\
\text { by dialysis }\end{array}$ & 50 & $248(220)^{*}$ \\
\hline At $48 \mathrm{hrs}$ & 43 & $180(162)^{*}$ \\
\hline At $96 \mathrm{hrs}$ & \\
\hline
\end{tabular}

*referred to standard body surface area i.e. $\mathrm{ml} / \mathrm{min} / 1.73 \mathrm{sq} \mathrm{m}$

in the patient's urine was almost four times higher during the second day as compared to the first day post-treatment, i.e. 1.5 and $5.5 \%$ of the iodine activity for first and second 24-hour periods. The table also shows the ${ }^{131} \mathrm{I}$ clearance calculated for the patient's residual kidney activity as well as the iodine clearances due to dialysis calculated for the two dialysis sessions. Finally, the lower part of the table shows the ${ }^{131}$ I clearances for patient No. 5 as calculated during her two dialysis sessions.

\section{DISCUSSION}

Over the last twenty-five years and particularly since the mid 1990s, there have been several reports in the literature of patients with end stage renal disease on haemodialysis or CPD who were treated with radioactive ${ }^{131} \mathrm{I}$, either for DTC or for persistent thyrotoxicosis. ${ }^{4-13,19-21}$ Two recent papers deal exclusively with patients on CPD, ${ }^{14,15}$ where the situation is similar to people with normal kidneys in the sense that "renal" plasma clearance of radioiodide is continuous, although considerably lower than that of individuals with normal renal function. Patients on CPD will not be further discussed here as they are not relevant to our cases. The cases on maintenance haemodialysis, on the other hand, are a category of their own in the sense that radioiodine removal basically happens only during dialysis sessions: thus, the radioiodide's handling and availability to the thyroid depend critically not only on the activity and the patient's residual renal function but also on the timing and frequency of dialysis treatments during the few days before and after ${ }^{131} \mathrm{I}$ administration. Publications concerning this latter category of patients have recently been reviewed by Holst et al 2005, who tried to highlight the pitfalls of both empirical and dosimetric approaches as well as to explain the differences in the recommendations regarding radioiodine therapy in the published cases with ESRD on haemodialysis. ${ }^{6}$

Radioidine-131 treatment for thyroid disease depends on the ability of high energy beta radiation emitted by this radiopharmaceutical ${ }^{22}$ to deliver a lethal dose to the thyroid cells which accumulate it. In the case of DTC, these high range particles would hopefully even reach and destroy adjacent cells with neoplastic potential and poor affinity for iodide: ${ }^{23}$ expression of the sodium iodide symporter (NIS) in the neoplastic cells varies and hence the ability of such cells to accumulate radioiodine may be variable. ${ }^{24}$

Despite the obvious similarities, the treatments with radioiodine for hyperthyroidism and DTC in patients with ESRD differ in two very important aspects: a) In cases of thyrotoxicosis there are alternatives to radioactive iodine treatment, which is not the case with thyroid carcinoma, and b) while in thyrotoxicosis the thyroid mass is well defined, it may be difficult to define accurately the location and amount of tissue to be treated in post-operative ${ }^{131} \mathrm{I}$ ablation of thyroid remnants in DTC, in the sense that further to thyroid remnants and metastases visualized by contemporary imaging techniques, it would be desirable also to treat micrometastases.

Ideally, in internal radiotherapy, one should be able to aim at and achieve an optimal radiation dose to thyroidal tissue while keeping incidental irradiation of other organs minimal. However, in the case of DTC, where the mass to be irradiated may be in the sense mentioned above indefinable, in practice this approach often fails to arrive at any useful con- 
clusions because of the large number of unknown factors. Furthermore, no randomized prospective studies have ever been possible for defining an optimal dose to the target tissue, mainly because of the nature of DTC, which has a very long natural history and slow course. As a result, most practitioners prescribe an empiric standard activity of ${ }^{131} \mathrm{I}$, depending on the stage of the disease, without attempting any dosimetry. ${ }^{1-3,23,25}$ Indeed, even in the treatment of thyrotoxicosis the approach of graded standard activities of ${ }^{131}$ I rather than dosimetric calculations is usually employed. ${ }^{26,27}$

As far as the administration of therapeutic doses of ${ }^{131}$ I to patients with ESRD is concerned, accurate dosimetry would be especially desirable, mainly because of the uncertainty introduced by the prolonged exposure to the higher ${ }^{131} \mathrm{I}$ blood levels during the time interval between the administration of radioiodine and the first post-therapy dialysis session. This is probably the reason that most of the cases published so far in the literature attempt or recommend either a dosimetric approach ${ }^{7,8,12}$ or some calculations based on a tracer study to modify their empirical activity. Nevertheless, the activities of ${ }^{131} \mathrm{I}$ in these studies vary widely, a fact commented on by Holst et al who reviewed and analysed the published cases of patients on haemodialysis treated with ${ }^{131}$ I. These authors suggest a mathematical model of their own to substitute for the empiric activities and calculate an optimal ${ }^{131}$ I activity for treating cases with of DTC or hyperthyroidism; however, the authors finally recommend using ${ }^{131}$ I dosimetry when available.

All dosimetric methods for ${ }^{131}$ I treatment depend on studying the kinetics of a tracer dose of ${ }^{131} \mathrm{I}$ prior to treatment. ${ }^{28,29}$ The most accurate of these are based on ${ }^{131}$ I plasma concentration measurements over several days after ingestion of the tracer dose; however, multiple plasma sampling may not be simple (or even desirable) in a patient with advanced renal disease. Still more important, the analysis by kinetic models assumes that there is a steady state and equilibrium of tracer concentrations between body compartments; these assumptions are not necessarily applicable in the case of patients on haemodialysis.

Several approaches for employment of external measurements after administration of a few $\mathrm{mCi}$ of
${ }^{131}$ I as tracer have also been used as an alternative to blood sampling; however, external measurements have additional disadvantages: they are inherently less accurate than plasma kinetics as they may be significantly affected by geometric factors and also require a tracer activity of the order of $74 \mathrm{MBq}(2$ $\mathrm{mCi}$ ) or higher. Some physicians feel that it is not desirable to administer mCi quantities of ${ }^{131} \mathrm{I}$ to a patient shortly to be given a therapy dose of ${ }^{131}$ I because of the possibility of thyroid "stunning".

It would appear, therefore, that using dosimetry and mathematical models to calculate the ${ }^{131} \mathrm{I}$ therapy activity in ESRD cases may have even more pitfalls and unpredictable factors in DTC patients than in normals. This conclusion is supported by the widely diverging therapy activities recommended in the aforementioned publications, which vary from reducing ${ }^{131} \mathrm{I}$ activities down to about $20 \%$ of the empiric activity ${ }^{4,9}$ to keeping the amount of ${ }^{131}$ I stable, ${ }^{7,12,13}$ or even to increasing the ${ }^{131}$ I activity up to $130 \%$ of that which would be prescribed for subjects with normal renal function. ${ }^{5,10}$ For all these reasons the validity of a practical approach based on previous pooled experience, i.e. an approach similar to that adopted already in most centres for ${ }^{131} \mathrm{I}$ treatment of DTC, should certainly be examined as it would be useful at least to those institutions where I 131 dosimetry is not available.

Having had the opportunity to treat 5 ESRD patients with ${ }^{131} \mathrm{I}$ for differentiated thyroid carcinoma, we thought it would be worthwhile to present an outline of our experience from treating such patients over the last 23 years. Although the information available in some of the cases was minimal, the absence of short-term side effects, the short-term success of the treatment with respect to thyroid remnant ablation, and the information concerning radiation safety, ${ }^{30}$ as well as the co-operation challenges presented by this kind of case might still be useful to others; so might also be our experience relating to retention and clearance of ${ }^{131} \mathrm{I}$, which were measured when this was feasible. Although no dosimetric calculations were used for the ${ }^{131}$ I activities given to our patients, we did measure the ${ }^{131} I$ clearances and patterns of ${ }^{131} I$ body retention where possible, both for future reference, in case an additional ${ }^{131}$ I dose should be given 
to the patient, as well as for its possible usefulness to other workers.

Irrespective of the method used to determine the amount of therapeutic ${ }^{131}$ I to be administered, there are several other important choices to be made and questions to be answered when treating patients with ESRD on haemodialysis. The first of these concerns the time of dialysis sessions in relation to ${ }^{131}$ I treatment. Concerning the pre-radioiodine treatment dialysis, there is generally speaking consensus in the literature that this should be performed immediately before the therapeutic dose so that the patient's plasma pool of stable iodine will be as low as possible. ${ }^{4,6}$

Recommendations for the time of the $1^{\text {st }}$ posttherapy dialysis, on the other hand, vary. Some suggest that this should be postponed so as to make sure that the thyroid radioiodine uptake will reach its maximum; ${ }^{4,6}$ this could be as much as 48 hours later. This is the approach that we adopted in our patients, as it has the additional advantage of fitting in with the usual schedule of dialysis for most patients, which is every second day. It also allows an extra day for ${ }^{131} \mathbf{I}$ decay before taking the patient to the renal ward.

Other workers recommend, however, that the first session be carried out at 24 hours to reduce the whole body radiation dose. ${ }^{8,9}$ It has also been suggested that having a dialysis session every day for the first five post-therapy days might have additional advantages in this respect. ${ }^{8}$ The differences in recommended ${ }^{131}$ I activities in the literature (whether in absolute terms or in $\%$ of the standard empirical activity) may be partly attributed to the different times and procedures of post ${ }^{131} \mathrm{I}$ therapy dialysis sessions. Since carrying dialysis at $24 \mathrm{hrs}$ post-iodine treatment might be considered roughly equivalent to administering half the amount of radioactive iodine and having the first dialysis treatment at 48 hours.

Although several publications in the literature recommend reduction of the therapy dose to significantly less than $40 \%,{ }^{4,6,9}$ only Daumerie et $\mathrm{al}^{9}$ actually used doses of that order for their patients, namely $25 \%$ of their standard dose (i.e. $25 \mathrm{mCi}$ ). It is of interest to note that all three of their patients required a second equal dose after six months, to a cumulative activity of $1850 \mathrm{MBq}(50 \mathrm{mCi})$. It is not clear from the paper whether administration of two instead of one ${ }^{131} \mathrm{I}$ treatments 6 months apart was a deliberate choice aimed at minimizing the impact on extra-thyroidal tissues such as bone marrow. Against any potential beneficial effects of this schedule on the dose to bone marrow, the desirability of controlling the DTC as soon as feasible and the possible risk of loss of differentiation and ability to concentrate ${ }^{131} \mathrm{I}$ of remnant thyroid cells should also be considered. Our aim when treating DTC in patients on dialysis because of ESRD is certainly the same as in patients with adequate kidney function, i.e. to eliminate all functioning thyroid tissue with one dose. One could even argue that this is even more important for ESRD patients as they need to be cancer-free in order to be considered for a kidney transplant. This seems to have been achieved, at least short-term, in the patients presented here; furthermore, none of the patients experienced any of the more common shortterm side effects such as nausea or sieladenitis, which might reasonably be considered to be a very rough measure of the effect of radiation on extrathyroid tissues. On the other hand, patients with ESRD are a high risk group for anaemia and this should also be taken into consideration.

Regarding other important parameters of ${ }^{131} \mathbf{I}$ treatment, the effective half life of radioiodine can vary widely, even in patients with normal renal function. North et $\mathrm{al}^{31}$ in their study of thyroidectomized DTC patients found values ranging from 7 to $105 \mathrm{hrs}$. This may be partly attributed to the varying effect of hypothyroidism (which is normally the state of the patient to be treated with ${ }^{131} \mathrm{I}$ unless recombinant $\mathrm{TSH}$ is to be given) in slowing down the kidney function..$^{32}$ In cases of ESRD this factor contributes only to the extent that the patient has some residual kidney function; such was the case of patient No. 2 in our series who excreted in the urine about $7 \%$ of the administered ${ }^{131} \mathrm{I}$ in the first $48 \mathrm{hrs}$. Iodide normally is freely filtered by the kidneys but largely reabsorbed by the kidney tubules. Meller et al in their publication ${ }^{16}$ report that in normal patients iodine clearance varies between $10-60 \mathrm{ml} / \mathrm{min}$; thus, the value of 1 to 3 $\mathrm{ml} / \mathrm{min}$ found by us in this particular patient seems reasonable for someone retaining less than $10 \%$ of 
normal kidney function. Iodine clearances during dialysis session have been reported as being about five times larger than those for normal kidneys: the clearance of $145 \mathrm{ml} / \mathrm{min}$ and $157 \mathrm{ml} / \mathrm{min}$ in case 2 , on the one hand, and 245 and $180 \mathrm{ml} / \mathrm{min}$ for case 5 , on the other, calculated for the respective patients during dialysis at 48 and 96 hours post ${ }^{131}$ I treatment are compatible with these reports and similar to the data published by Culpepper et al. ${ }^{13}$

Finally, the percent elimination of ${ }^{131}$ I during the haemodialysis sessions of 43 to $65 \%$ were similar to those reported for other patients in the literature. ${ }^{7,9}$ In only one (case No. 5) of the two patients who had a second haemodialysis at the hospital was the per cent elimination of ${ }^{131}$ I significantly lower in the $2^{\text {nd }}$ dialysis treatment compared to the first (43 vs 50 $\%$ ), a finding similar to that reported by Culpepper et al. ${ }^{13}$

Regarding the possibility of long-term side effects, there is now considerable experience of treating thyroid cancer with ${ }^{131} \mathrm{I}$ as this has been available for about 60 years; thus, an appreciable increase of the risk of serious side effects, such as leukemia, bladder or colorectal cancer, has been reported only in cases of administration of cumulative ${ }^{131} \mathrm{I}$ activities higher than $29600 \mathrm{MBq}(800 \mathrm{mCi}) .{ }^{33,34}$ A recent cohort study from three European countries, ${ }^{35}$ however, suggests that the increase in the risk of developing radiation induced tumours is linearly related to cumulative activities of administered Iodine 131, so even smaller cumulative activities would result in a small increase of cancer risk. Furthermore, some recent techniques measuring minor damage to blood elements, such as lymphocytes, report that some radiotoxicity can occur even with activities of the order of $3700 \mathrm{MBq}$ $(100 \mathrm{mCi}) \cdot{ }^{36,37}$ Even so, the expected increase of risk of new malignancies at these levels is small. Concerning otherwise healthy DTC patients, it has been argued that even in cases of high cumulative activities, the increase in the risk for leukaemia is rather small. When judged against the benefits that ${ }^{131} \mathrm{I}$ ablation offers to the patient, this risk is worth taking. ${ }^{38}$ On the other hand, it might be argued that patients with ESRD are a particularly vulnerable group.

Finally, independently of how important the impact of a activity of the order of $3700 \mathrm{MBq}(100 \mathrm{mCi})$ may be in this particular group of patients, good cooperation between all the specialists involved with the patient's nephrologists, arranging if necessary for transfusion at the appropriate time and so on, could probably lead to safe management of the patient, even if the whole body dose might be somewhat higher than the theoretically ideal.

In conclusion, the experience from the cases presented in this paper would encourage us to continue treating DTC in patients with ESRD with ${ }^{131} \mathrm{I}$ when indicated. An empirical activity of $1110-1480 \mathrm{MBq}$ for localized disease or $2590 \mathrm{MBq}$ for locoregional progression (30-40 and $70 \mathrm{mCi}$, respectively, or $40-50 \%$ of our dose for normal individuals) appears to be effective as well as safe. This should be administered as soon as possible after dialysis, while the $48 \mathrm{hr}$ dialysis schedule of the patient could be carried on after ${ }^{131}$ I treatment. Finally, only the first of post-therapy haemodialysis sessions need take place during the ${ }^{131}$ I therapy hospitalization. At institutions where sophisticated dosimetric techniques are available, ${ }^{39}$ further refinements of dosimetry may achieve good control of DTC with further reduction of Iodine 131 activities administered, which certainly remains the ideal aim.

\section{REFERENCES}

1. Mazzaferri EL, Kloos RT, 2001 Current approaches to primary therapy for papillary and follicular thyroid cancer. J Clin Endocrinol Metab 86: 1447-1463.

2. Mazzaferri EL, 2004 Editorial: A randomized trial of remnant ablation- in search of an impossible dream? J Clin Endocrinol Metab 89: 3662-3664.

3. Mazzaferri EL, Massoll N, 2002 Management of papillary and follicular (differentiated) thyroid cancer: new paradigms using recombinant hyman thyrotropin. Endocr Relat Cancer 9: 227-247.

4. Howard N, Glasser M, 1981 Iodine 131 ablation therapy for a patient on maintenance haemodialysis. Br J Radiol 54: 259

5. Magne N, Magne J, Bracco J, Bussiere F, 2002 Disposition of Radioiodine 131 therapy for thyroid carcinoma in a patient with severely impaired renal function on chronic dialysis: a case report. Jpn J Clin Oncol 32: 202-205.

6. Holst JP, Burman KD, Atkins F, Umans JG, Jonklaas J, 2005 Radioiodine therapy for thyroid cancer and hyperthyroidism in patients with end-stage renal disease on haemodialysis. Thyroid 15: 1321-1331.

7. Mello AM, Isaacs R, Petersen J, Kronenberg S, McDou- 
gall IR, 1994 Management of thyroid papillary carcinoma with radioiodine in a patient with end stage renal disease on haemodialysis. Clin Nucl Med 19: 776-781.

8. Jimenes GR, Moreno AS, Gonzalez EN, et al, 2001 Iodine-131 treatment of thyroid papillary carcinoma in patients undergoing dialysis for chronic renal failure: a dosimetric method. Thyroid 11: 1031-1034.

9. Daumerie C, Vynkier S, Caussin J, et al, 1996 Radioiodine treatment of thyroid carcinoma in patients on maintenance haemodialysis. Thyroid 6: 301-304.

10. Morrish DW, Filipow LJ, McEwan AJ, et al, $1990{ }^{131} \mathrm{I}$ treatment of thyroid papillary carcinoma in a patient with renal failure. Cancer 66: 2509-2513.

11. Jawa A, Pendergrass M, 2003 A case of Recombinant TSH for the treatment of papillary thyroid cancer in a patient with end stage renal disease. Program $75^{\text {th }}$ Annual American Thyroid Association meeting September 2003 no 43.

12. Sinsakul M, Ahmad A, 2004 Radioactive ${ }^{131}$ I use in end stage renal disease: nightmare or nuisance? Semin Dial 17: 53-56.

13. Culpepper RM, Hirsch JI, Fratkin MJ, 1992 Clearance of ${ }^{131} \mathrm{I}$ by hemodialysis. Clin Nephrol 38: 110-114.

14. Kaptein EM, Levenson H, Siegel ME, Gadallah M, Akmal M, 2000 Radioiodine dosimetry in patients with end-stage renal disease receiving continuous ambulatory peritoneal dialysis treatment. J Clin Endocrinol Metab 85: 3058-3064.

15. Toubert M, Michel C, Metivier F, Peker MC, Rain J, 2001 Iodine-131 ablation therapy for a patient receiving peritoneal dialysis. Clin Nucl Med 26: 302-305.

16. Meller J, Sahimann CO, Becker W, 2002 Nuclear Medicine studies in the dialysis patient. Semin Dial 15: 269-276.

17. Alevizaki M, Alevizaki C, Ikkos D, Skordalakis E, 1973 Radioiodine uptake values of euthyroid patients in Greece Minerva Medica Greca 1: 255-267.

18. Kottou S, Papadimitriou D, Molfetas M, et al, 2001 Radiation protection of thyroid cancer patients receiving ${ }^{131}$ I therapy: some considerations IAEA $2001 \mathrm{CN} 85-202$ : 379-382.

19. Miyasaka Y, Yoshimura M, Tabata S, et al, 1997 Successful treatment of a patient with Graves' disease on haemodialysis complicated by antithyroid drug induced granulocytopeneia and angina pectoris. Thyroid 7: 621624.

20. Demko TM, Tulchinsky M, Miller KL, Ceung JY, Groff JA, 1998 Diagnosis and radioablation treatment of toxic multinodular goiter in a haemodialysis patient. Am J Kidney Dis 31: 698-700.

21. Nibhanupudy JR, Hamilton W, Sridhar R, et al, 1993 Iodine 131 treatment of hyperthyroidism in a patient on dialysis for chronic renal failure. Am J Nephrol 13: 214-217.

22. Stabin MG, Siegel JA, 2003 Physical models and dose factors for use in internal dose assessment. Health Phys
85: 294-310.

23. Mazzaferri EL 1996 Thyroid Tumors. Radioiodine and other treatments and outcomes. In: Werner and Ingbar's The Thyroid: A Fundamental and Clinical Text $7^{\text {th }}$ Edition pp, 922-945. Edited by LE Braverman and RD Utiger Lippincott-Raven Publishers Philadelphia.

24. Spitzweg C, Morris JC, 2002 Sodium Iodide Symporter (NIS) and Thyroid. Hormones (Athens) 1: 22-34.

25. Tzavara I, Vlassopoulou B, Alevizaki C, et al, 1999 Differentiated thyroid cancer: a retrospective analysis of 832 cases from Greece. Clinical Endocrinology 50: 643-654.

26. Alevizaki C, Alevizaki-Harhalaki M, Ikkos D, 1985 Radioiodine treatment of thyrotoxicosis: dose required for and some factors affecting the induction of hypothyroidism. Eur J Nucl Med 14: 450-454.

27. Kaplan MM, Meier DA, Dworkin HJ, 1998 Treatment of hyperthyroidism with radioactive iodine. Endocrinol Metab Clin North Am 27: 205-223.

28. Cavalieri RR, McDougall IR 1996 In Vivo Isotopic Tests and Imaging. In: Werner and Ingbar's The Thyroid: A Fundamental and Clinical Text $7^{\text {th }}$ Edition pp352-357. Edited by LE Braverman and RD Utiger LippincottRaven Publishers Philadelphia.

29. O'Connor MK, Cullen MJ, Malone JF, 1979 The value of a tracer dose in predicting the kinetics of therapeutic doses of ${ }^{131} \mathrm{I}$ in thyrotoxicosis. Br J Radiol 52: 719-726.

30. Homer L, Smith AH, 2002 Radiation protection issues of treating hyperthyroidism with ${ }^{131} \mathrm{I}$ in patients on haemodialysis. Nucl Med Commun 23: 261-264.

31. North DL, Shearer DR, Hennesey JV, Donovan GL, 2001 Effective half-life of ${ }^{131} \mathrm{I}$ in thyroid cancer patients. Health Phys 81: 325-329.

32. Montenegro J, Gonzalez O, Saracho R, Aguire R, Gonzalea O, Martinez I, 1996 Changes in renal function in primary hypothyroidism. Am J Kidn Dis 27: 195-198.

33. Maxon H, Smith HS, 1990 Radioiodine 131 in the diagnosis and treatment of metastatic well-differentiated thyroid cancer. Endocrinol Metab Clin North Am 19: 685-718.

34. Edmonds CJ, Smith T, 1986 The long-term hazards of the treatment of thyroid cancer with radioiodine. $\mathrm{Br} \mathrm{J}$ Radiol 59: 45-51.

35. Rubino C, deVathaire F, Dottorini ME, et al, 2003 Second primary malignancies in thyroid cancer patients. $\mathrm{Br}$ J Cancer 89: 1638-1644.

36. de Keizer B, Hoekstra A, Koijnenberg MW, et al, 2004 Bone marrow dosimetry and safety of high ${ }^{131}$ I activities given after recombinant human TSH to treat metastatic differentiated thyroid carcinoma. J Nucl Med 45: 15491554.

37. Watanabe N, Kanegane H, Kinuya S, et al, 2004 The radiotoxicity of ${ }^{131} \mathrm{I}$ therapy of thyroid cancer: assessment by micronucleus assay of B lymphocytes. J Nucl Med 45: 608-611.

38. Wong JB, Kaplan MM, Meyer KB, Pauker SG, 1990 Abla- 
tive radioactive therapy for apparently localized thyroid carcinoma. A decision analytic perspective. Endocrinol Metab Clin North Am 19: 741-760.

39. Cooper DS, Doherty GM, Haugen BR, et al, 2006 The
American Thyroid Association Guidelines Taskforce. Management guidelines for patients with thyroid nodules and differentiated thyroid cancer. Thyroid 16: 109-142. 